\title{
Evaluation of Oral Status and Tobacco Use in a Rural Population and Testing a Scale Developed to Rate Oral Status: A Pilot Study
}

\author{
Rekha P. Shenoy ${ }^{1}$, Mallika S. Shetty ${ }^{2}$, K. Prashanth Shenai ${ }^{3}$ \\ and M. Shashidhar Kotian ${ }^{4}$ \\ ${ }^{1}$ Department of Public Health Dentistry, Yenepoya Dental College, Deralakatte, Mangalore, India \\ ${ }^{2}$ Department of Prosthodontics and Crown and Bridge, Yenepoya Dental College, Deralakatte, \\ Mangalore, India \\ ${ }^{3}$ Department of Oral Medicine \& Radiology, Yenepoya Dental College, Deralakatte, Mangalore, India \\ ${ }^{4}$ Department of Community Medicine, Kasturba Medical College, Light House Hill Road, Mangalore, \\ India
}

Correspondence should be addressed to: Rekha P. Shenoy; merekhap@yahoo.co.in

Received Date: 30 October 2013; Accepted Date: 20 December 2013; Published Date: 21 January 2014

Academic Editor: Reiko Yamanaka

Copyright ( 2014 Rekha P. Shenoy, Mallika S. Shetty, K. Prashanth Shenai and M. Shashidhar Kotian. Distributed under Creative Commons CC-BY 3.0

\begin{abstract}
The objectives of this investigation were to evaluate the oral status and tobacco use of subjects residing in rural areas to provide epidemiological data for planning oral health programs and to test a scale developed to rate oral status. A cross-sectional investigation was conducted among first-visit subjects visiting the out-patient dental clinics of two rural hospitals during a sixmonth period. Data were collected by interviews and clinical examinations. Criteria evaluated in the proposed scale were based on the status of the oral tissues in disease and health. Differences in proportions were compared using the Chi squared test and a p-value of $<0.05$ was considered statistically significant. The study population comprised 614 patients $(43.6 \%$ male, $56.4 \%$ female) aged between four and 80 . Only $1.6 \%$ subjects had an intact dentition while $17.9 \%$ presented with a healthy periodontium. Two hundred forty-five subjects had undergone prosthetic rehabilitation. Tobacco use was reported by $13.3 \%$ subjects and they accounted for $88 \%$ of the oro-mucosal lesions observed. Once daily tooth cleansing was reported by $68.2 \%$ subjects while $2.3 \%$ did not practice any oral hygiene measures. The scale used mirrored the subjects' oral status accurately. To conclude, the poor oral status of this population was compounded by lack of awareness about the presence of oral disease. A renewed stress on implementation of oral health promotion strategies for rural populations seems critical in the present context and the proposed scale needs to be validated by studies on larger population groups.
\end{abstract}

Keywords: Oral status, rating scale, rural, tobacco use.

Cite this Article as: Rekha P. Shenoy, Mallika S. Shetty, K. Prashanth Shenai and M. Shashidhar Kotian(2014), "Evaluation of Oral Status and Tobacco Use in a Rural Population and Testing a Scale Developed to Rate Oral Status: A Pilot Study," Journal of Research and Practice in Dentistry, Vol. 2014 (2014), Article ID 353599, DOI: 10.5171/2014.353599 


\section{Introduction}

Oral diseases have considerable impact on individuals and communities, as a result of the pain, suffering, impairment of function and reduced quality of life they impose (Varenne et al., 2005; WHO, 2003). In India, oral diseases have been largely neglected by health planners and, therefore, oral health-care programs have not been integrated into national and community health programs even though a National Oral Health Policy for India was drafted in 1985 (National Oral Health Policy for India, 1986), redrafted in 1995 (Government of India, 1995), and strategies for implementing a pilot program were finalized in 2003 (Government of India and the All India Institute of Medical Sciences, 2003).

Serious constraints exist regarding availability and accessibility to essential oral health-care services among people living in rural areas (Varenne et al., 2005) due to geographical and economic barriers. A lack of definitive data on the oral health needs of this population is another contributing factor in the Indian context. Epidemiological data are a prime requisite to aid authorities planning health care systems especially when they represent populations that so far have had very limited access to formal oral health care (Pekiner et al., 2010).

India has the highest prevalence of oral cancer in the world, $95 \%$ of which is linked to the use of tobacco. This condition has a high morbidity and mortality; therefore, early diagnosis is crucial in ensuring patient survival. Oral cancer is always preceded by some pre-cancerous lesion or condition which can be diagnosed early since the oral cavity is easily accessible for examination (Government of India, 2005).

Oral status of any individual or population groups is usually evaluated using indices for specific oral conditions. However, there is lack of a rating scale which gives a complete picture of the oral cavity based on all conditions of disease and health.
Therefore, the objectives of this investigation were to evaluate the oral status and tobacco use of subjects residing in rural habitats and to provide epidemiological data for planning oral health programs. Also, the investigators made an attempt to test a scale which was developed to rate oral status.

\section{Material and Methods}

Subjects: A cross-sectional survey was conducted for a six-month period (March to August 2011) on subjects visiting the outpatient dental clinics of two rural hospitals in Karnataka State, India. These clinics are located in areas where, as of now, no data exists on the oral health needs of the population. All first-visit subjects reporting to these facilities for dental care were informed of the nature of the investigation and their consent sought. Those who either refused to or were unable to undergo oral examination were excluded. Ethical approval for the study was obtained from the Institutional Review Board. Informed consent was obtained from all participants.

Data Collection: Data were collected by interviews and clinical examinations. (a) Interviews - Demographic characteristics assessed were age and level of education [illiterate/primary school/high school/graduate/post-graduate]. Other measures elicited through interviews included oral hygiene practices [tooth brushing frequency], satisfaction with prosthesis

[function/esthetics/comfort/retention] if used, history of tobacco use [nil/smokeless tobacco/smoked tobacco] and self-rating of oral status

[excellent/good/satisfactory/poor]. (b) Oral examination - Condition of the dentition [decayed/missing/restored teeth, attrition, abrasion], periodontium [healthy, gingivitis (bleeding on probing), periodontitis (bleeding + recession + mobility)], oro-mucosal lesions [present/absent], oral hygiene status [debris/calculus/stains - present/absent], use of prosthesis [fixed and removable], 
condition of the prosthesis [intact/illfitting/fractured/with occlusal wear/with deposits], and rating of patients' oral status [excellent/good/fair/poor] were assessed clinically. Data collection were carried out in the out-patient dental clinics by two trained and calibrated investigators using plane mouth mirrors, No. 5 explorers and periodontal probes. Calibration trials were performed before the initiation of data collection to ensure intra- and interexaminer reliability (Cohen's Kappa statistic), which averaged 0.86 .

The criteria which were evaluated in the proposed scale were based on the status of the oral tissues in disease and health. Investigators rated the oral status of subjects as follows:

Score $\mathbf{0}=$ if healthy dentition / decayed teeth and cervical abrasions are restored / healthy periodontium / healthy oral mucosa / absence of dental deposits / prosthetic rehabilitation has been done where required and the prosthesis is functional, and patient is satisfied with the prosthesis / no history of tobacco use.

Score $\mathbf{1}=$ if more than $50 \%$ of decayed teeth and cervical abrasions are restored / gingivitis present / presence of dental deposits / prosthetic rehabilitation has been done but the prosthesis is faulty, or patient is dissatisfied with the prosthesis.

Score $\mathbf{2}$ = if more than $25 \%$ but less than $50 \%$ of decayed teeth and cervical abrasions are restored / periodontitis present / prosthetic rehabilitation has not been done where required / tobacco use present.

Score 3 = if less than $25 \%$ of decayed teeth and cervical abrasions are restored / oromucosal lesion present.

The scores obtained were totaled and then rated as Excellent (0-2), Good (3-6), Fair (7-10) and Poor (11-13). Tobacco use present was categorized in Score 2, not in Score 1, to increase weightage to the habit. Construct validity of the scale (Scores 0-3) was done by two experts according to the criteria used.

Statistical Analysis: Subjects were categorized into five age groups: $\leq 15,16-$ 30, $31-45,46-60$, and $\geq 61$ years. Data were analyzed using the Statistical Package for Social Sciences (SPSS) Version 17.0 program for Windows. Differences in proportions were compared using the Chi squared test and a p-value of $<0.05$ was considered as statistically significant.

\section{Results}

A total of 614 first-visit subjects (43.6\% male, $56.4 \%$ female) ranging in age between four and 80 years (mean age $36.21 \pm 17.12$ years), who consented to participate, were examined and interviewed (Table 1). Exclusions numbered 28.

Table 1: Distribution of Subjects Based on Age and Gender

\begin{tabular}{|l|l|l|l|}
\hline $\begin{array}{l}\text { Age group } \\
\text { (in years) }\end{array}$ & $\begin{array}{l}\text { Males } \\
\text { n (\%) }\end{array}$ & $\begin{array}{l}\text { Females } \\
\text { n (\%) }\end{array}$ & $\begin{array}{l}\text { Total } \\
\text { n (\%) }\end{array}$ \\
\hline$\leq 15$ & $30(11.2 \%)$ & $37(10.7 \%)$ & $67(10.9 \%)$ \\
\hline $16-30$ & $64(23.9 \%)$ & $131(37.9 \%)$ & $195(31.8 \%)$ \\
\hline $31-45$ & $56(20.8 \%)$ & $99(28.5 \%)$ & $155(25.3 \%)$ \\
\hline $46-60$ & $83(31.0 \%)$ & $59(17.1 \%)$ & $142(23.1 \%)$ \\
\hline$\geq 61$ & $35(13.1 \%)$ & $20(5.8 \%)$ & $55(8.9 \%)$ \\
\hline Total & $268(100 \%)$ & $346(100 \%)$ & $614(100 \%)$ \\
\hline
\end{tabular}
$(\mathrm{p}<0.001)$

About 51\% subjects had attended primary school, $40.7 \%$ had a high school education while $2.9 \%$ were illiterates. In the 16-30year age group, $65 \%$ subjects had a high school degree; among the 31-45-, 46-60and $\geq 61$-year-olds, about $50 \%$ subjects had received schooling up to the primary level. There were significant differences between 
the age groups with regard to education ( $\mathrm{p}$ $<0.001$ ).

Table 2 shows the distribution of subjects based on condition of their dentition. Only
$1.6 \%$ subjects had an intact dentition. Condition of the dentition differed significantly by gender and age $(\mathrm{p}<0.001)$, and education $(\mathrm{p}<0.001)$.

Table 2: Distribution of Subjects Based on the Condition of Dentition

\begin{tabular}{|l|l|}
\hline Condition of the dentition & $\begin{array}{l}\text { Total } \\
\mathbf{n}(\mathbf{\%})\end{array}$ \\
\hline $\begin{array}{l}\text { Subjects with varying combinations of decayed, } \\
\text { missing and filled teeth }\end{array}$ & $537(87.5 \%)$ \\
\hline Subjects with tooth attrition & $10(1.6 \%)$ \\
\hline Subjects with cervical abrasions & $2(0.3 \%)$ \\
\hline $\begin{array}{l}\text { Subjects with varying combinations of the above } \\
\text { conditions }\end{array}$ & $55(9.0 \%)$ \\
\hline Subjects with intact dentition & $10(1.6 \%)$ \\
\hline Total & $\mathbf{6 1 4}(\mathbf{1 0 0} \%)$ \\
\hline
\end{tabular}

Gingivitis was present in 50.8\% study subjects, $31.3 \%$ subjects suffered from periodontitis while $17.9 \%$ had a healthy periodontium. Table 3 summarizes the periodontal status with respect to gender and age. Educational levels of the subjects' were found to significantly influence their periodontal status $(\mathrm{p}=0.002)$.

Table 3: Distribution of Subjects Based on Age and Periodontal Status

\begin{tabular}{|c|c|c|c|c|c|c|c|c|}
\hline \multirow[t]{2}{*}{$\begin{array}{l}\text { Age } \\
\text { (in years) }\end{array}$} & \multicolumn{2}{|l|}{ Healthy } & \multicolumn{2}{|c|}{$\begin{array}{l}\text { Gingivitis } \\
\text { (Bleeding } \\
\text { probing) }\end{array}$} & \multicolumn{2}{|c|}{$\begin{array}{l}\text { Periodontitis } \\
\text { (Bleeding+Recession+ } \\
\text { Mobility) }\end{array}$} & \multicolumn{2}{|l|}{ Total } \\
\hline & Male & Female & Male & Female & Male & Female & Male & Female \\
\hline $\begin{array}{l}\leq 15 \\
\text { n (\%) }\end{array}$ & $\begin{array}{c}9 \\
(19.6 \%)\end{array}$ & $\begin{array}{c}15 \\
(23.4 \%)\end{array}$ & $\begin{array}{c}21 \\
(18.1 \%)\end{array}$ & $\begin{array}{c}22 \\
\quad(11.2 \%) \\
\end{array}$ & $0(0 \%)$ & $0(0 \%)$ & $\begin{array}{c}30 \\
(11.2 \%)\end{array}$ & $\begin{array}{l}37 \\
(10.7 \%)\end{array}$ \\
\hline $\begin{array}{l}16-30 \\
\text { n (\%) }\end{array}$ & $\begin{array}{c}9 \\
(19.6 \%)\end{array}$ & $\begin{array}{l}22 \\
(34.4 \%)\end{array}$ & $\begin{array}{c}52 \\
(44.8 \%)\end{array}$ & $\begin{array}{c}106 \\
(54.1 \%)\end{array}$ & $\begin{array}{c}3 \\
(2.8 \%)\end{array}$ & $\begin{array}{c}3 \\
(3.5 \%)\end{array}$ & $\begin{array}{c}64 \\
(23.9 \%)\end{array}$ & $\begin{array}{l}131 \\
(37.9 \%)\end{array}$ \\
\hline $\begin{array}{l}31-45 \\
\text { n (\%) }\end{array}$ & $\begin{array}{c}3 \\
(6.5 \%)\end{array}$ & $\begin{array}{l}5 \\
(7.8 \%)\end{array}$ & $\begin{array}{c}30 \\
(25.9 \%)\end{array}$ & $\begin{array}{c}55 \\
(28.1 \%)\end{array}$ & $\begin{array}{c}23 \\
(21.7 \%)\end{array}$ & $\begin{array}{c}39 \\
(45.4 \%)\end{array}$ & $\begin{array}{c}56 \\
(20.9 \%)\end{array}$ & $\begin{array}{c}99 \\
(28.6 \%)\end{array}$ \\
\hline $\begin{array}{l}46-60 \\
\text { n (\%) }\end{array}$ & $\begin{array}{c}15 \\
(32.6 \%)\end{array}$ & $\begin{array}{c}12 \\
(18.8 \%)\end{array}$ & $\begin{array}{c}10 \\
(8.6 \%)\end{array}$ & $\begin{array}{l}10 \\
(5.1 \%)\end{array}$ & $\begin{array}{c}58 \\
(54.7 \%)\end{array}$ & $\begin{array}{c}37 \\
(43.0 \%)\end{array}$ & $\begin{array}{c}83 \\
(31.0 \%)\end{array}$ & $\begin{array}{l}59 \\
(17.1 \%)\end{array}$ \\
\hline $\begin{array}{l}\geq 61 \\
\text { n (\%) }\end{array}$ & $\begin{array}{c}10 \\
(21.7 \%)\end{array}$ & $\begin{array}{c}10 \\
(15.6 \%)\end{array}$ & $\begin{array}{l}3 \\
(2.6 \%)\end{array}$ & $\begin{array}{c}3 \\
(1.5 \%)\end{array}$ & $\begin{array}{c}22 \\
(20.8 \%)\end{array}$ & $\begin{array}{c}7 \\
(8.1 \%)\end{array}$ & $\begin{array}{c}35 \\
(13 \%)\end{array}$ & $\begin{array}{l}20 \\
(5.7 \%)\end{array}$ \\
\hline $\begin{array}{l}\text { Total } \\
\text { n (\%) }\end{array}$ & $\begin{array}{c}46 \\
(100 \%)\end{array}$ & $\begin{array}{c}64 \\
(100 \%)\end{array}$ & $\begin{array}{l}116 \\
(100 \%)\end{array}$ & $\begin{array}{l}196 \\
(100 \%)\end{array}$ & $\begin{array}{c}106 \\
(100 \%)\end{array}$ & $\begin{array}{c}86 \\
(100 \%)\end{array}$ & $\begin{array}{c}268 \\
(100 \%)\end{array}$ & $\begin{array}{l}346 \\
(100 \%)\end{array}$ \\
\hline
\end{tabular}

The labial and buccal mucosae, tongue, floor of the mouth, and soft and hard palates were assessed for presence of oromucosal lesions. The prevalence was $7.8 \%$. Among males, prevalence of mucosal lesions was highest in the 46-60-year-olds followed by the $\geq 61$-year- age group while among females, prevalence was highest in the 31-45-year-olds followed by the 46-60year- age group. Debris was present in $56.8 \%$ subjects, calculus in $55.9 \%$ subjects and stains in $32.4 \%$ subjects. A significant association was found between age and oral hygiene among males $(\mathrm{p}=0.008)$ as well as females ( $p<0.001)$. Presence of dental deposits was significantly related to periodontal status $(\mathrm{p}<0.001)$ and condition of dentition ( $p<0.001)$; however, it was not associated with the educational qualifications of the subjects $(\mathrm{p}$ $=0.074$ ).

Of the 614 subjects, 245 (39.9\%) had undergone prosthetic rehabilitation (Table 4). Prosthetic rehabilitation was found to be significantly influenced by the gender $(\mathrm{p}$ $<0.001)$ and educational level $(\mathrm{p}<0.001)$ of the subjects. 
Table 4: Distribution of Subjects Who HaveUndergone Prosthetic Rehabilitation

\begin{tabular}{|l|l|}
\hline Type of prosthesis & $\begin{array}{l}\text { Total } \\
\text { n (\%) }\end{array}$ \\
\hline Fixed partial dentures & $108(44.1 \%)$ \\
\hline Removable partial dentures & $85(34.7 \%)$ \\
\hline Complete dentures & $46(18.7 \%)$ \\
\hline $\begin{array}{l}\text { Combination of fixed and removable } \\
\text { dentures }\end{array}$ & $6(2.5 \%)$ \\
\hline Total & $\mathbf{2 4 5 ( 1 0 0 \% )}$ \\
\hline
\end{tabular}

Condition of the prosthesis among subjects who have undergone prosthetic rehabilitation is shown in Table 5.

Table 5: Distribution Based on the Condition of the Prosthesis among Subjects Who Have Undergone Prosthetic Rehabilitation

\begin{tabular}{|l|l|}
\hline Condition of the prosthesis & $\begin{array}{l}\text { Total } \\
\text { n (\%) }\end{array}$ \\
\hline Ill-fitting & $34(13.9 \%)$ \\
\hline Fractured & $26(10.6 \%)$ \\
\hline With occlusal wear & $9(3.7 \%)$ \\
\hline With deposits above / Multiple & $22(9.0 \%)$ \\
\hline $\begin{array}{l}\text { Combinations of } \\
\text { defects }\end{array}$ & $40(16.3 \%)$ \\
\hline Intact / Satisfactory & $114(46.5 \%)$ \\
\hline Total & $\mathbf{2 4 5 ( 1 0 0 \% )}$ \\
\hline
\end{tabular}

Condition of the prosthesis was significantly associated with education $(\mathrm{p}<$ $0.001)$, and age and gender $(p=0.003$ for males and $\mathrm{p}<0.001$ for females). Among the prosthetically rehabilitated, $76.7 \%$ were satisfied with the appliance; however, $20 \%$ complained of discomfort and $3.3 \%$ of poor retention. Subject opinion when evaluated by education ( $\mathrm{p}<0.001)$, and age and gender $(\mathrm{p}=0.007$ for males and 0.005 for females) showed significant differences.
Tobacco use was reported by 82 subjects (Table 6) and they accounted for $88 \%$ of the oro-mucosal lesions observed in this study. These subjects were then referred for further diagnostic tests and treatment. Tobacco use was not linked to education ( $\mathrm{p}$ $=0.237$ ); however, it was significant vis-àvis age among female subjects $(\mathrm{p}=0.040)$.

Table 6: Distribution of Subjects Based on the Type of Tobacco Used

\begin{tabular}{|l|l|}
\hline Type of tobacco used & $\begin{array}{l}\text { Total } \\
\text { n (\%) }\end{array}$ \\
\hline Smoked tobacco & $60(73.2 \%)$ \\
\hline Smokeless tobacco & $17(20.7 \%)$ \\
\hline Users of both forms & $5(6.1 \%)$ \\
\hline Total & $\mathbf{8 2 ( 1 0 0 \% )}$ \\
\hline
\end{tabular}

When frequency of oral hygiene practice was assessed, $68.2 \%$ reported a once daily cleansing ritual, $27.4 \%$ brushed their teeth twice daily, $2.1 \%$ more than twice daily and
$2.3 \%$ did not practice any oral hygiene measures. A significant association was found for oral hygiene practices with age and gender [males $(p<0.001)$ and females 
$(p=0.016)]$, education, oral hygiene status and periodontal status ( $p<0.001$ for all three parameters) and condition of dentition $(p=0.004)$.

When asked to evaluate their oral status, $0.7 \%$ subjects rated their oral health as excellent, $27 \%$ as good, $60.2 \%$ as satisfactory and $12.1 \%$ said their oral health was poor. Significant differences were observed for self-rating by gender, age and educational qualifications $(\mathrm{p}=$ $0.015,0.001$ and 0.009 , respectively).

Investigators rated oral status of the 614 subjects as follows: $0.2 \%(\mathrm{n}=1)$ as excellent, $18.7 \%(n=115)$ as good, $59.4 \%$ $(n=365)$ as fair and $21.7 \%(n=133)$ as poor. These ratings differed significantly by gender and age $(\mathrm{p}<0.001)$, education $(\mathrm{p}=$ $0.034)$, condition of dentition $(p=0.001)$, periodontal status $(\mathrm{p}<0.001)$, oral hygiene status $(\mathrm{p}<0.001)$, condition of prosthesis ( $p=0.271)$, tobacco use $(p<0.001)$, and self-rating by subjects ( $\mathrm{p}<0.001)$. The scale developed by the investigators mirrored the subjects' oral status accurately.

\section{Discussion}

Studies in recent times(Kumar et al., 2010; Patro et al., 2008; Pekiner et al., 2010; Varenne et al., 2004; Varenne et al., 2005) have attempted to elicit oral status of population groups as an indicator of effectiveness of the oral health care system. As rural populations are denied quality care due to an inequitable distribution of facilities, this investigation evaluated the oral and prosthetic status, tobacco use, and oral hygiene practices of subjects visiting two rural dental clinics which cater to the oral needs of the local population to a large degree.

A strength of the present study was the age range of subjects assessed was more encompassing than surveyed in recent epidemiological studies (Kumar et al., 2010; Patro et al., 2008; Pekiner et al., 2010; Varenne et al., 2004; Varenne et al., 2005). This wide range reveals the pattern of oral disease occurrence in the population of this region. The female predominance seen in the present study mirrors previous studies conducted in differing geographic zones (Kumar et al., 2010; Patro et al., 2008; Pekiner et al., 2010; Varenne et al., 2004) and may be attributed to a rising awareness among females about the importance of oral health.

Education or knowledge is believed to be an important component of expressed need. This study population had better educational qualifications than detected by a previous survey in North Indian subjects by Kumar et al (2010) which should have reflected on the oral health status. However, most subjects were afflicted with oral disease with only $1.6 \%$ revealing a healthy dentition. Dental caries prevalence was higher than reported by previous investigations on urban and rural populations (Kumar et al., 2010; Patro et al., 2008; Varenne et al., 2004; Varenne et al., 2005). Conversely, the levels of periodontal disease were lower than reported by Kumar et al (2010) and it was significantly linked to age and education. This paradoxical existence of high levels of dental disease within populations having basic educational qualifications raises the question as to whether motivation is the key to prevention, control and treatment of oral disease.

Higher levels of calculus were observed than reported by other authors in Burkina Faso, Africa (Varenne et al., 2004; Varenne et al., 2005), but less than found in Turkish populations by Pekiner et al (2010) and rural Indian populations by Kumar et al (2010). Poor oral hygiene, a contributor to oral disease, is a uniform finding relating to the high disease levels in various studies (Kumar et al., 2010; Pekiner et al., 2010; Varenne et al., 2004) and can be attributed to the oral hygiene practices prevalent in the population. The frequency of once-daily oral cleansing found was lower than reported by other studies (Kumar et al., 2010; Patro et al., 2008) but the number of those practicing twice daily tooth brushing was higher. This could be attributed to the higher educational status of the study subjects, which agrees with the study by Kumar et al (2010). Presence of oral lesions 
was linked to tobacco use but the prevalence was lower than earlier reported in India by Kumar et al (2010) but higher than found in Ouagadougou, Burkina Faso by Varenne et al (2005).

As a pointer to their better educational qualifications, more subjects had undergone prosthetic rehabilitation, and the number of removable complete and partial denture users was significantly higher than found in a previous study (Kumar et al., 2010). As determined by the investigators, $53.5 \%$ of these subjects were using a faulty prosthes is which needed correction; however, only $23.3 \%$ expressed dissatisfaction with their prosthesis.

Tobacco users in this study numbered less than found in previous investigations on similar populations (Kumar et al., 2010; Patro et al., 2008). This can be attributed to the higher educational levels of subjects in this investigation even though the other studies were conducted in states having higher literacy rates than Karnataka (Government of India, 2011). All three studies demonstrated the predominance of smoked tobacco use.

A large number of subjects rated their oral status as satisfactory. This may be due to the oral conditions not compromising or significantly reducing oral function, or a lack of pain. A wide variation was observed between subjects' self-rating and investigators' rating in the Excellent, Good and Poor categories. Most subjects seemed unaware of the presence of oral disease, thereby not seeking remedial care for their resolution.

\section{Study Limitations}

The oro-mucosal lesions were not categorized; however, those with lesions were informed of their presence and referred for specialized care. Also, the proposed scale needs to be validated by studies on larger population groups.

\section{Conclusion}

The present study found that the poor oral status of this population was compounded by lack of awareness on the presence of oral disease even though a majority of subjects had undergone primary schooling. These findings should be used as a baseline to increase focus on oral health promotion strategies for rural populations by formulating public health programs stressing on primary and secondary care for prevention and early treatment of oral disease. The scale developed can not only be used to rate oral status but could also be used as a patient education aid in a dental clinic.

\section{References}

"Census of India," (2011).Ministry of Home Affairs, Government of India. [17/04/2012] Available: http://theonlinegk.wordpress.com/2011/ 04/02/literacy-rate-in-indian-statecensus-2011.

\begin{abstract}
'National Oral Health Care Programme Implementation Strategies,' (2003).Initiative of the Directorate General of Health Services, Ministry of Health and Family Welfare, Government of India and the all India Institute of Medical Sciences, New Delhi.
\end{abstract}

"National Oral Health Policy," (1995).Prepared by Core Committee Appointed by The Ministry of Health and Family Welfare, Government of India, New Delhi.

"National Oral Health Policy For India," (1986). Journal of the Indian Dental Association, 58(10):378-401.

"NCMH Background Papers-Burden of Disease in India," (2005). Ministry of Health \& Family Welfare, Government of India, New Delhi, September 2005.

Kumar, A., Virdi, M., Veeresha, K. L. \& Bansal, V. (2010). 'Oral Health Status and Treatment Needs of Rural Population of Ambala, Haryana, India,' The Internet Journal of Epidemiology, 8(2). DOI: 10.5580/1367.

Patro, B. K., Kumar, R. B., Goswami, A., Mathur, V. P. \&Nongkynrih, B. (2008). 
"Prevalence of Dental Caries among Adults and Elderly in an Urban Resettlement Colony of New Delhi," Indian Journal of Dental Research, 19(2):95-98.

Pekiner, F., Gumru, B., Borahan, M. 0. \& Aytugar, E. (2010). "Evaluation of Demands and Needs for Dental Care in a Sample of the Turkish Population," European Journal of Dentistry, 4(2):143-149.

Petersen, P. E. (2003). "World Health Organization Continuous Improvement of Oral Health in the 21st Century - The Approach of the WHO Global Oral Health Programme," The World Oral Health Report 2003, Community Dentistry and Oral Epidemiology, Geneva, Switzerland.
Varenne, B., Msellati, P., Zoungrana, C., Fournet, F. \& Salem, G. (2005). "Reasons for Attending Dental-Care Services in Ouagadougou, Burkina Faso," Bulletin of the World Health Organization, 83(9):650-655.

Varenne, B., Petersen, P. E. \& Ouattara, S. (2004). "Oral Health Status of Children and Adults in Urban and Rural Areas of Burkina Faso, Africa," International Dental Journal, 54(2):83-89. 